\title{
Primary glomerular disease with extraglomerular vascular osmiophilic deposits ${ }^{1}$
}

\author{
A. H. NAGI, F. ALEXANDER, AND R. LANNIGAN \\ From the Departments of Pathology, Queen's University of Belfast, $N$ Ireland, and University of \\ Calgary, Canada
}

SYNOPSIS The ultrastructural changes in renal arterioles and capillaries from three cases of epimembranous nephropathy, one case of minimal change, and one case of minimal change with mild focal proliferation are presented. In addition to the usual subepithelial deposits on the glomerular capillary basement membranes in the cases of epimembranous nephropathy, osmiophilic granular苍 deposits were observed on the outer aspect of extraglomerular vascular basement membranes. No ${ }_{0}$ clinical history of hypertension was obtained and there was no histological evidence of renal ${ }_{-}^{\curvearrowright}$ hypertensive vascular disease.

Membranous glomerulonephritis, first recognized by Bell in 1950, is a well defined disorder unrelated to other forms of glomerulonephritis. The distinct character of the basement membrane changes in the absence of any cellular proliferation has led to this entity being renamed epimembranous nephropathy (White, 1969). The glomerular ultrastructure has been recorded by Churg, Grishman, Goldstein, Yunis, and Porush (1965) and also by Ehrenreich and Churg (1968); the latter authors also described extraglomerular renal vascular alterations, which were visible by light microscopy. These lesions were seen in elderly patients or in those with epimembranous nephropathy and hypertension. Extraglomerular vascular osmiophilic deposits are described in three young, non-hypertensive patients, with epimembranous nephropathy, one with focal proliferative glomerulonephritis, and one with a minimal change lesion.

\section{Materials and Methods}

Renal tissue obtained by open biopsy was divided into three parts, two large and one small. One of the larger blocks was fixed in $10 \%$ formaldehyde, embedded in paraffin and 3 to 4 micron sections were stained with haematoxylin and eosin, periodic acid/Schiff's reagent, and silver methanamine. The second of the larger blocks was frozen and 3-4 micron cryostat sections were used for immunofluorescent

${ }^{1}$ Requests for reprints should be addressed to Dr A. H. Nagi, Department of Pathology, Lahore General Hospital, Lahore, Pakistan. Received for publication 8 December 1971. studies. The small block was further divided immediately into approximately $1 \mathrm{c} \mathrm{mm}$ blocks and fixed in buffered osmium tetroxide and processed for electron microscopy.

\section{Case 1}

This 32-year-old woman was admitted to hospital $\overrightarrow{\overrightarrow{0}}$ because of ankle oedema for two months. On exami- 3 nation, puffiness of the face was noted. Her blood pressure on admission was $110 / 70 \mathrm{~mm} \mathrm{Hg}$ and did? not rise above $125 / 80 \mathrm{~mm} \mathrm{Hg}$ during her stay in hospital. Laboratory investigations showed urinary:protein excretion of up to $10.5 \mathrm{~g}$ per 24 hours. The 3 . total serum protein was down to $4.6 \mathrm{~g} \%$ and serum electrophoresis showed a fall in albumin $(2 \cdot 1 \mathrm{~g} \%) \frac{2}{3}$ and a rise in gamma globulin. The serum cholesterol rose to $358 \mathrm{mg} \%$. Serum creatinine was between $0.6 \%$ and $0.9 \mathrm{mg} \%$. Creatinine clearance varied between $\frac{D}{2}$ $128 \mathrm{ml} / \mathrm{min}$ and $92 \mathrm{ml} / \mathrm{min}$. The blood urea was $50 \mathrm{mg} \%$, blood sugar $82 \mathrm{mg} \%$, and the ESR went $\tilde{N}$ up to $63 \mathrm{~mm}$ in one hour. A clinical diagnosis of the $\mathrm{N}$ nephrotic syndrome was made.

\section{LIGHT MICROSCOPY}

Thirty-five glomeruli were examined at three levels $\stackrel{\circ}{\subset}$ of the block. There was no increase in cellularity and $\stackrel{\Phi}{\mathscr{D}}$ the suggested capillary basement membrane thicken- ing on haematoxylin-and-eosin-stained sections (Fig. 1) was confirmed by PAS staining. Silver $\overrightarrow{\mathbb{D}}$ methenamine staining showed projections on the $\frac{\rho}{\mathbb{P}}$ epithelial aspect of the glomerular capillary base- $\stackrel{\AA}{2}$ ment membrane (Fig. 2). The tubules appeared 


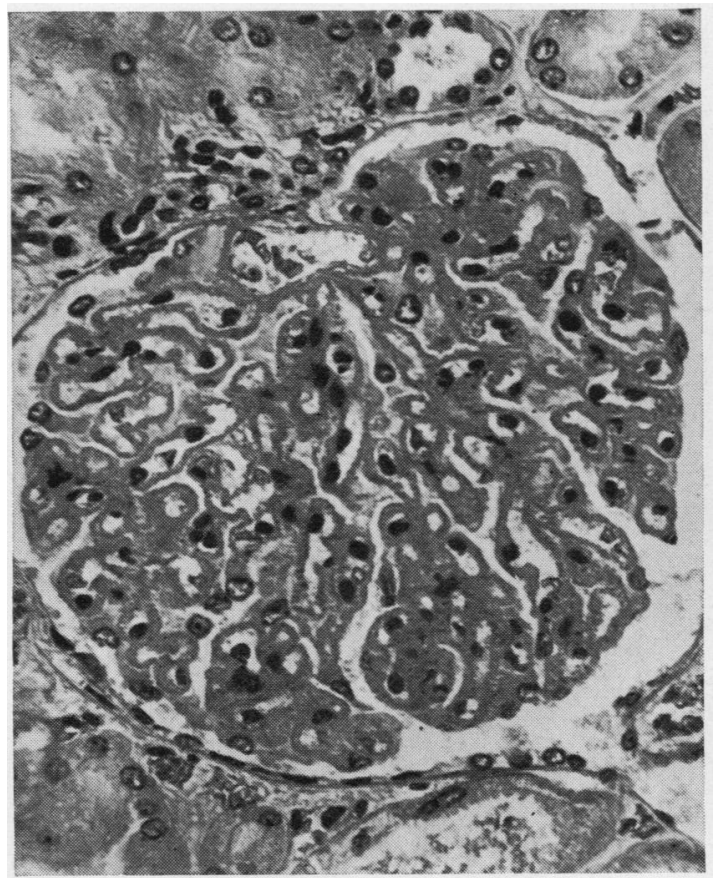

Fig. 1.

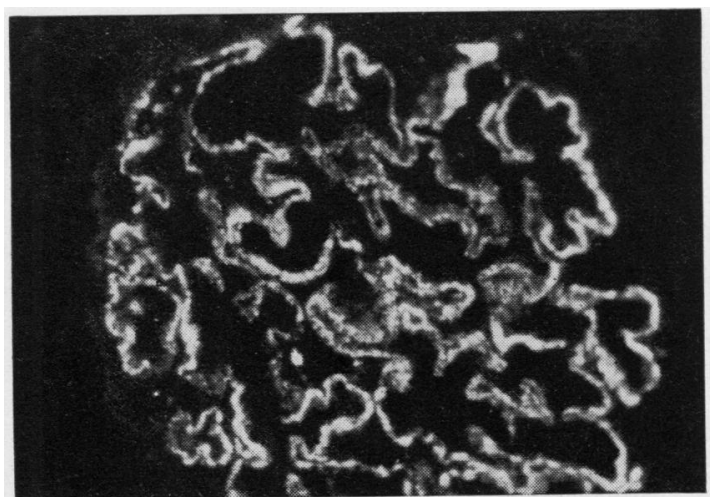

Fig. 3.

Fig. 1 Case 1: a glomerulus showing thickened capillary walls resulting in the narrowing of their lumina. $H$ and $E \times 460$.

Fig. 2 Case 1: portion of a glomerulus showing thickened basement membrane which shows methenaminesilver-positive projections (arrow) towards its epithelial aspect. Methenamine-silver $\times 1056$.

Fig. 3 Case 1: fluorescent micrograph of a glomerulus stained to demonstrate the characteristic beaded pattern of $I g G$ along the capillary walls $\times 410$. $3^{*}$

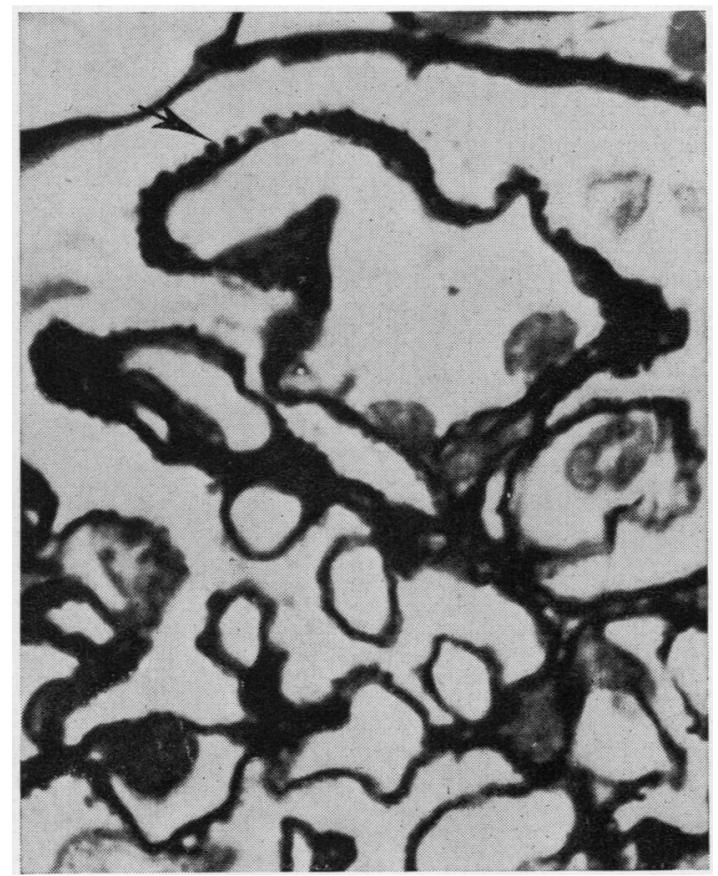

Fig. 2.

normal. Afferent arterioles and small intralobular arteries showed no histological abnormality. A diagnosis of epimembranous nephropathy was made. This diagnosis was supported by immunofluorescent microscopy which showed the characteristic beaded pattern using antihuman IgG and $\mathrm{B}_{1} \mathrm{C}$ component of complement (Fig. 3). Antifibrin stains were negative.

\section{ELECTRON MICROSCOPY}

The glomerular basement membrane was thickened. Numerous electron-dense, subepithelial, osmiophilic deposits were seen (Fig. 4). Foot processes were lost over most capillary loops. The tubular epithelial cells contained a few protein droplets in their cytoplasm. Two of the five blocks examined showed extraglomerular arterioles which had moderately thick walls due to numerous electron-dense osmiophilic deposits along the outer aspect of the basement membrane. These deposits were similar to those on the glomerular basement membrane in both density and granule size (Fig. 5).

\section{Case 2}

A 25-year-old man was admitted to hospital because of slight oedema of the ankles and face for five months. The highest blood pressure level recorded 


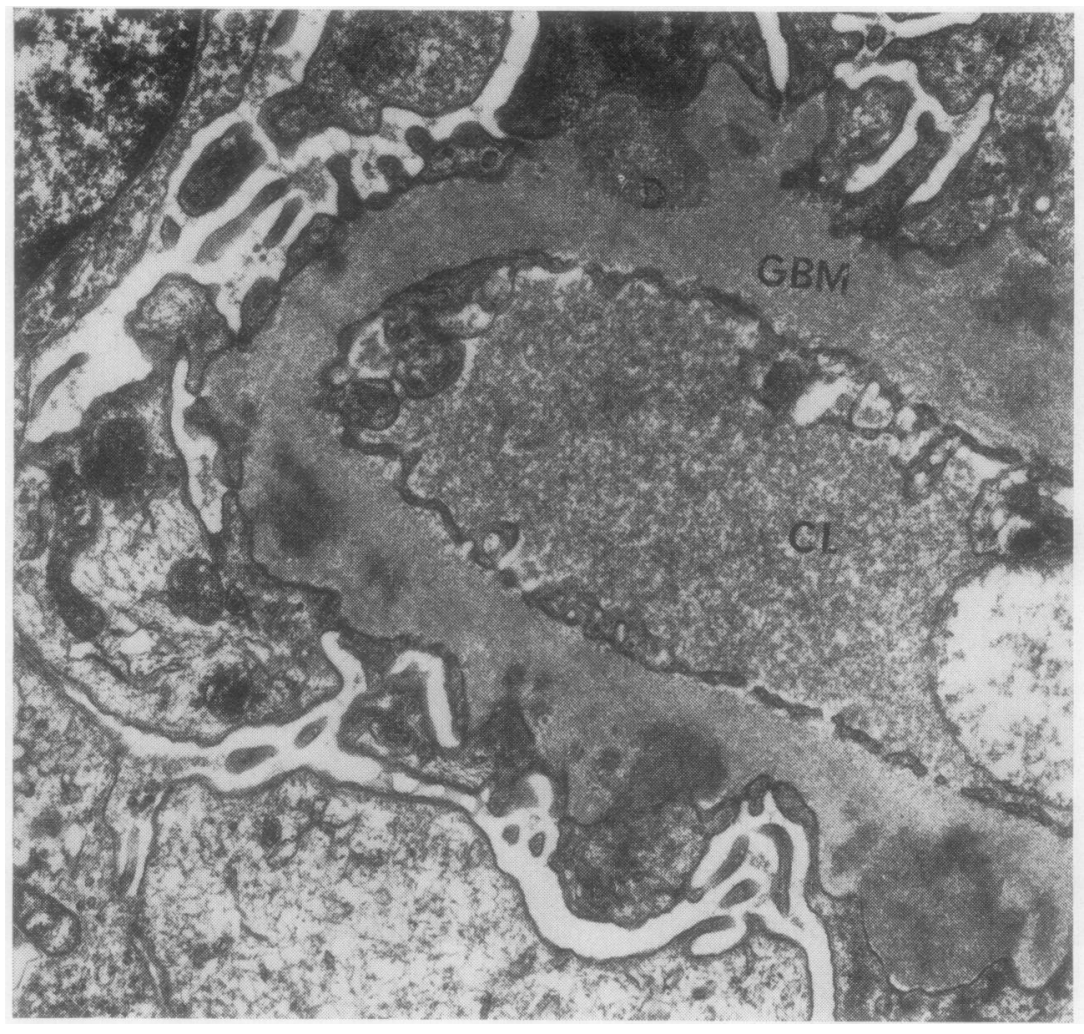
Fig. 4 Case 1: electron
micrograph of a glomerular capillary loop (CL) showing $\stackrel{\mathbb{Q}}{\AA}$ numerous osmiophilic deposits (D) towards the epithelial aspect of an irregularly thickened basement membrane $(\mathrm{GBM}) \times 9400$.

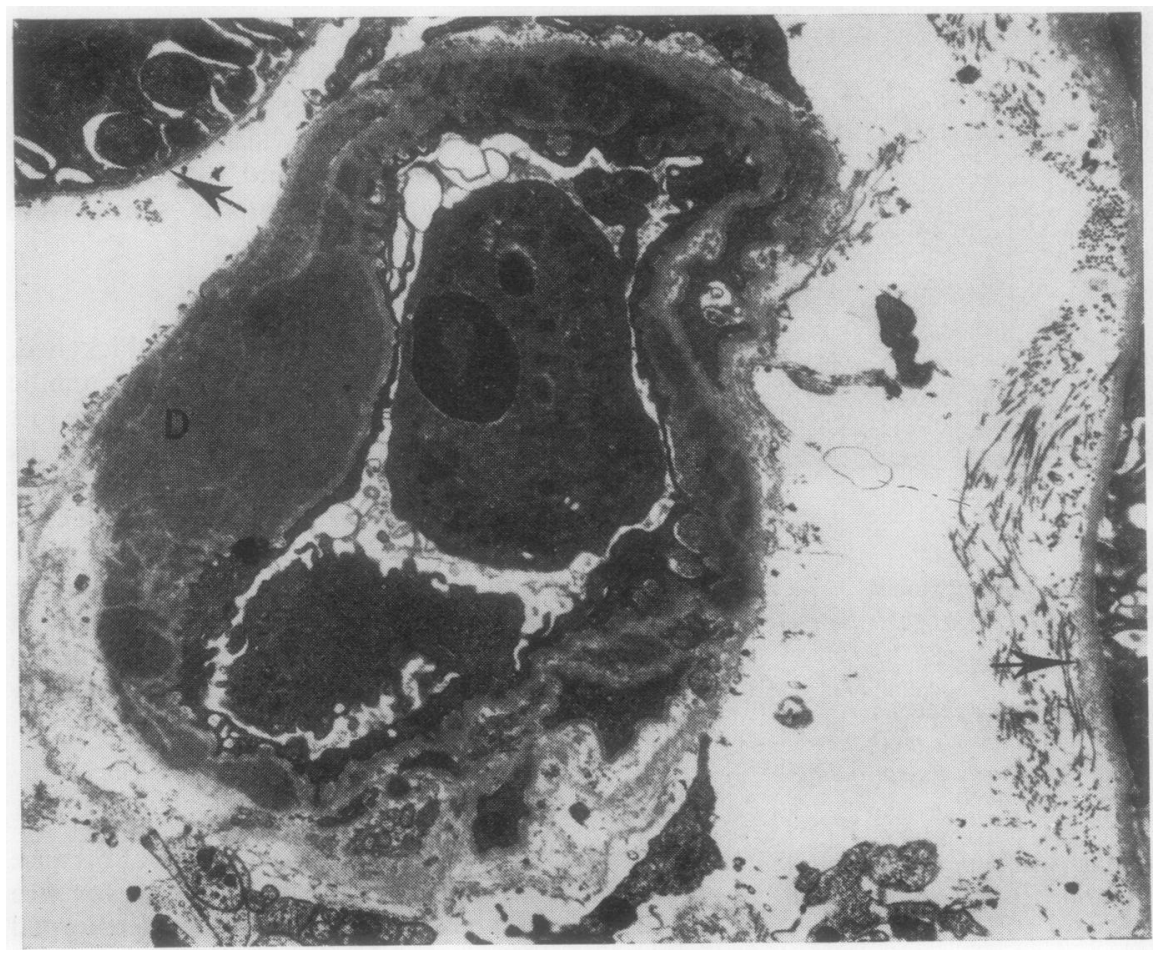

Fig. 5 Case 1: electron micrograph of an extraglomerular blood vessel showing numerous large osmio- $\frac{D}{D}$ philic deposits (D) in its wall. Parts of two N tubules (arrows) are also included $\times 6200$. N 


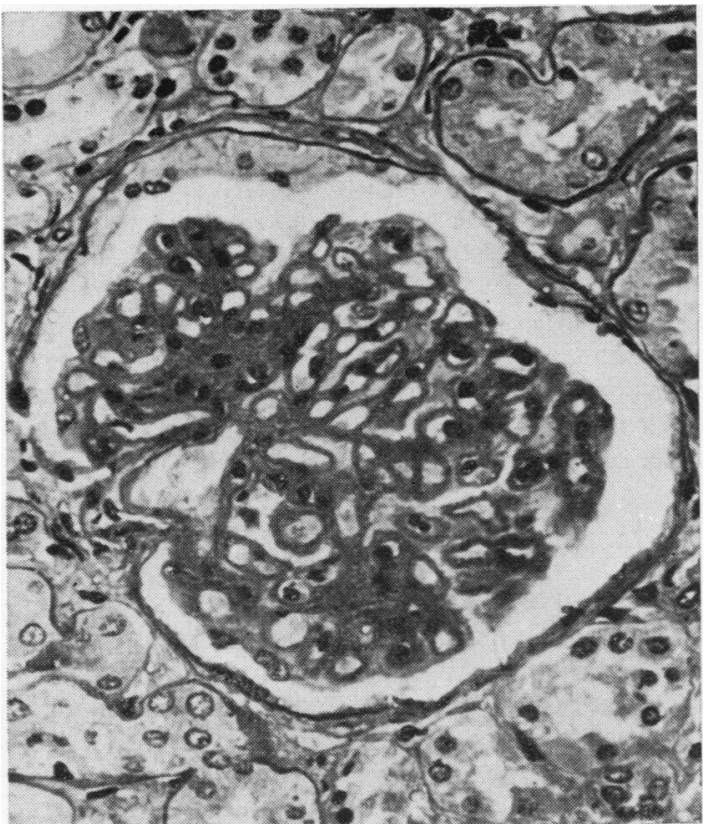

Fig. 6.

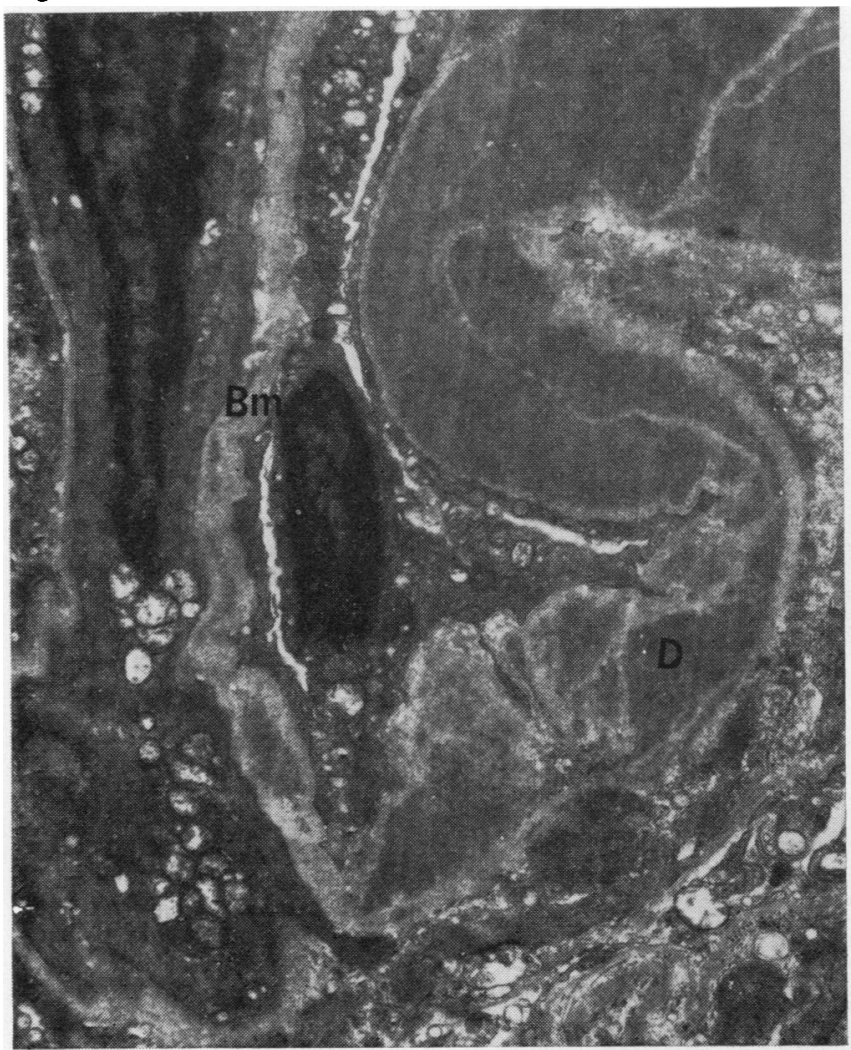

Fig. 7. was $135 / 70 \mathrm{~mm} \mathrm{Hg}$. The total serum protein ranged between 3.7 and $5.5 \mathrm{~g} \%$ and urinary protein loss varied from $4.8 \mathrm{~g}$ to $23 \mathrm{~g}$ per 24 hours. The serum albumin was seen to be low $(1.6 \mathrm{~g} \%)$ and the gamma globulins increased on serum electrophoresis. The serum cholesterol was $440 \mathrm{mg} \%$. Serum creatinine was between 0.8 and $1.6 \mathrm{mg} \%$ and creatinine clearance varied from $90 \mathrm{ml} / \mathrm{min}$ to $71 \mathrm{ml} / \mathrm{min}$. The blood urea was $58 \mathrm{mg} \%$, the ESR $35 \mathrm{~mm}$ in one hour, and the blood sugar $80 \mathrm{mg} \%$. A clinical diagnosis of the nephrotic syndrome was made, and open renal biopsy was carried out.

\section{LIGHT MICROSCOPY}

Thirty-nine glomeruli were present in the biopsy. The histological appearance of the glomeruli was similar to that described in case 1 (Fig. 6). The tubules contained pink hyaline casts and some of them were lined by pale-staining, lipid-containing cells. The blood vessels showed no arteriolar hyalinization. Immunofluorescent staining was similar to that observed in case 1 , but one small artery showed fluorescence with antihuman IgG only. No
Fig. 6 Case 2: a glomerulus showing thickened capillary basement membrane resulting in the narrowing of their lumina. $P A S \times 380$.

Fig. 7 Case 2: electron micrograph of an extraglomerular blood vessel showing marked thickening of its wall. The basement membrane (Bm) contains masses of osmiophilic deposits (D) $\times 9200$. 


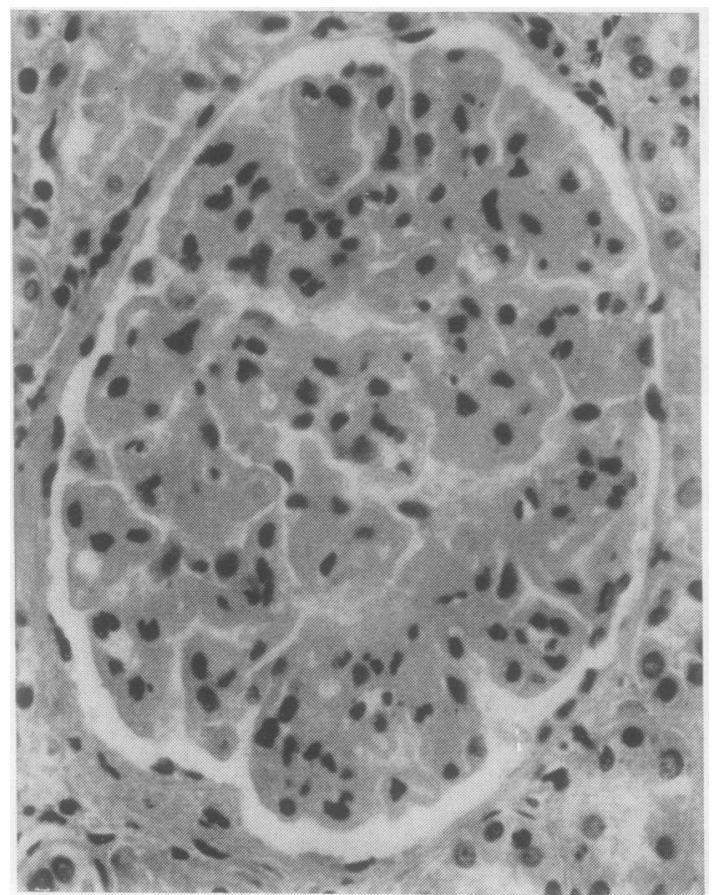

Fig. 8.

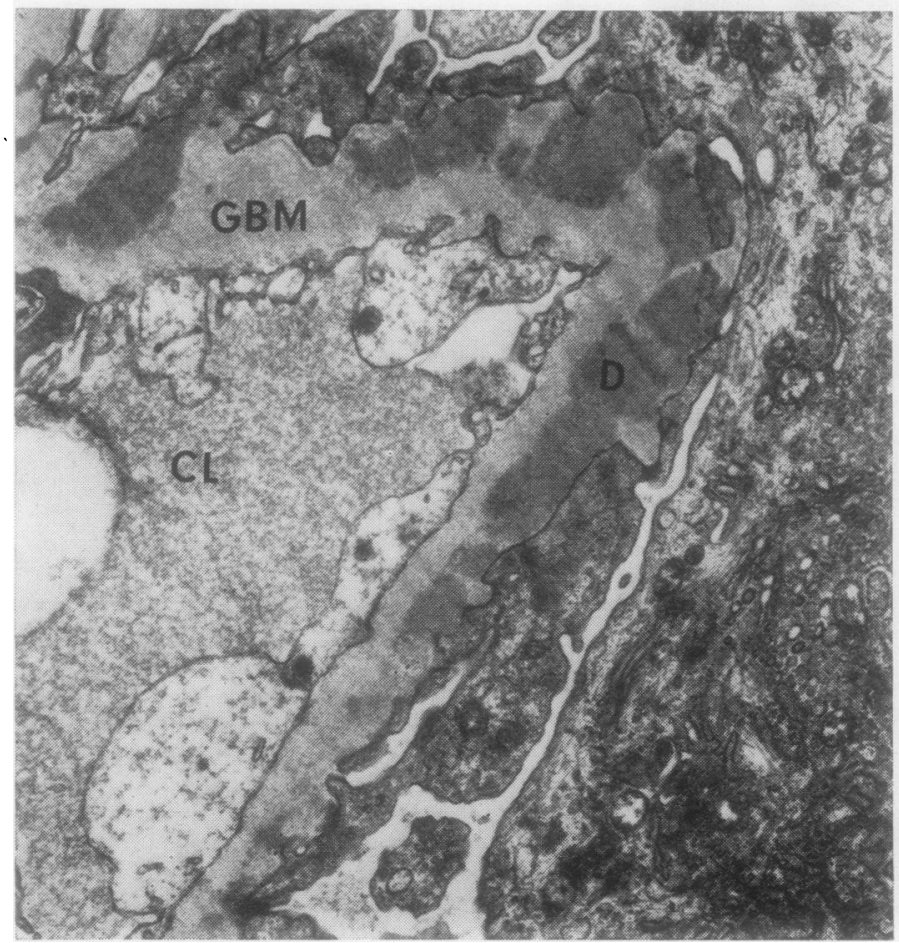

Fig. 8 Case 3: a glomerulus showing grossly thickened capillary walls resulting in marked narrowing of the lumina. $H$ and $E \times 440$.

Fig. 9 Case 3: electron micrograph of a capillary loop (CL) showing numerous subepithelial deposits (D) on the glomerular basement membrane (GBM) $\times 8800$. fluorescence was seen with antifibrin. A diagnosis of epimembranous nephropathy was made.

ELECTRON MICROSCOPY

The ultrastructural alterations in this biopsy were similar to, but more severe than those seen in case 1 . Subepithelial electron-dense osmiophilic deposits were more numerous per capillary loop. Numerous protein droplets were observed in the tubular epithelial cell cytoplasm. A thick-walled extraglomerular arteriole, seen in one of five blocks examined, had numerous osmiophilic deposits along the outer aspect of the basement membrane (Fig. 7).

\section{Case 3}

This 30-year-old woman was admitted to hospital with bilateral ankle oedema for 12 months. Some puffiness of the face was observed on clinical inspection. The highest recorded blood pressure reading was $140 / 85 \mathrm{~mm} \mathrm{Hg}$. Urinary protein excretion was as high as $14.9 \mathrm{~g}$ per 24 hours. The total serum protein ranged between $4.6 \mathrm{~g} \%$ and $5.8 \mathrm{~g} \%$ with a low serum albumin, $1.8 \mathrm{~g} \%$, and a relative increase in gamma globulin. The serum cholesterol was $319 \mathrm{mg} \%$.

Fig. 9. 


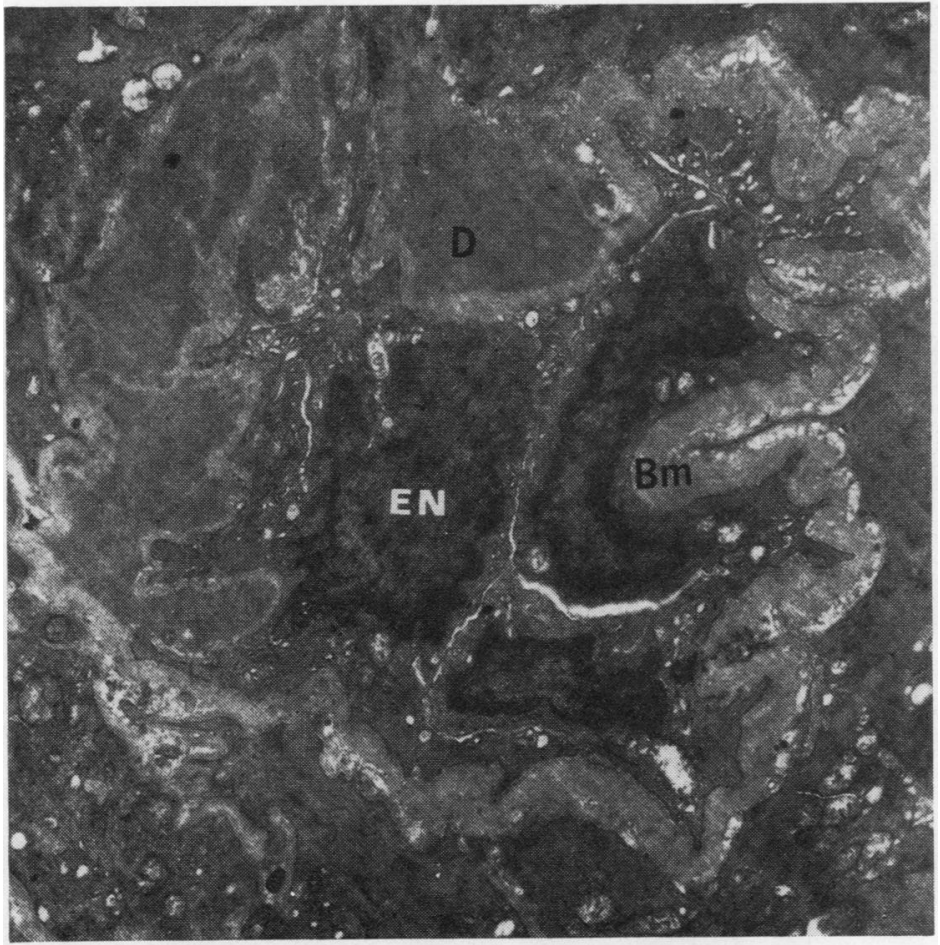

Fig. 10 Case 3: electron micrograph of an extraglomerular blood vessel showing osmiophilic deposits (D) within the basement membrane $(\mathrm{Bm})$. Three endothelial cells (EN) are also seen inside the blood vessel $\times 6100$.

Serum creatinine rose to $3.7 \mathrm{mg} \%$ and creatinine clearance was as low as $10 \mathrm{ml} / \mathrm{min}$ though usually over $20 \mathrm{ml} / \mathrm{min}$. The blood urea rose to $42 \mathrm{mg} \%$, the ESR was $57 \mathrm{~mm}$ after one hour, and blood sugar on two occasions was not more than $86 \mathrm{mg} \%$.

\section{LIGHT MICROSCOPY}

The 23 glomeruli observed in this biopsy were of low cellularity and showed moderately severe thickening of the capillary walls resulting in narrowing of capillary lumina (Fig. 8). PAS and silver methenamine stains demonstrated basement membrane thickening with projections on its epithelial aspect. There was patchy mild tubular atrophy. The blood vessels showed no detectable lesion. Glomerular immunofluorescence was similar to that in case 1. Arteriolar fluorescence was not observed and there was no fluorescence with antifibrin. A diagnosis of epimembranous nephropathy was made.

\section{ELECTRON MICROSCOPY}

The glomerular changes were similar to, but more severe than in the previous cases (Fig. 9). Two of the six blocks examined contained extraglomerular vessels. These arterioles were thick-walled, with a finely granular, electron-dense material deposited within and on the outer aspect of the basement membrane (Fig. 10). Protein droplets were prominent in the tubular epithelium.

\section{Case 4}

This 8-year-old boy was brought to his family practitioner by his mother, who had noticed definite oedema $(+++)$ of the feet and some puffiness around the eyes. One week later, following undetermined treatment, the boy was sent to the Royal Belfast Hospital for Sick Children where he was noted to have mild ankle oedema $(+)$, blood pressure $125 / 75 \mathrm{~mm} \mathrm{Hg}$, and no history of upper respiratory tract infection. His laboratory findings were ASOT less than 166 units; urinary protein $3.6-5.8 \mathrm{~g}$ per 24 hours; total serum protein $3.9 \mathrm{~g} \%$ (albumin $1.3 \mathrm{~g} \%$ and globulin $2.6 \mathrm{~g} \%$ ), blood urea $49 \mathrm{mg} \%$, serum cholesterol $328-492 \mathrm{mg} \%$, blood sugar $38 \mathrm{mg} \%$, total white cell count $15400 / \mathrm{ml}$, and ESR $52 \mathrm{~mm}$ in the first hour. A clinical diagnosis of the nephrotic syndrome was made and he was treated with steroids. Following a good initial response for approximately six months, his condition deteriorated again and a renal biopsy was performed two years after the onset of his illness. Since that 


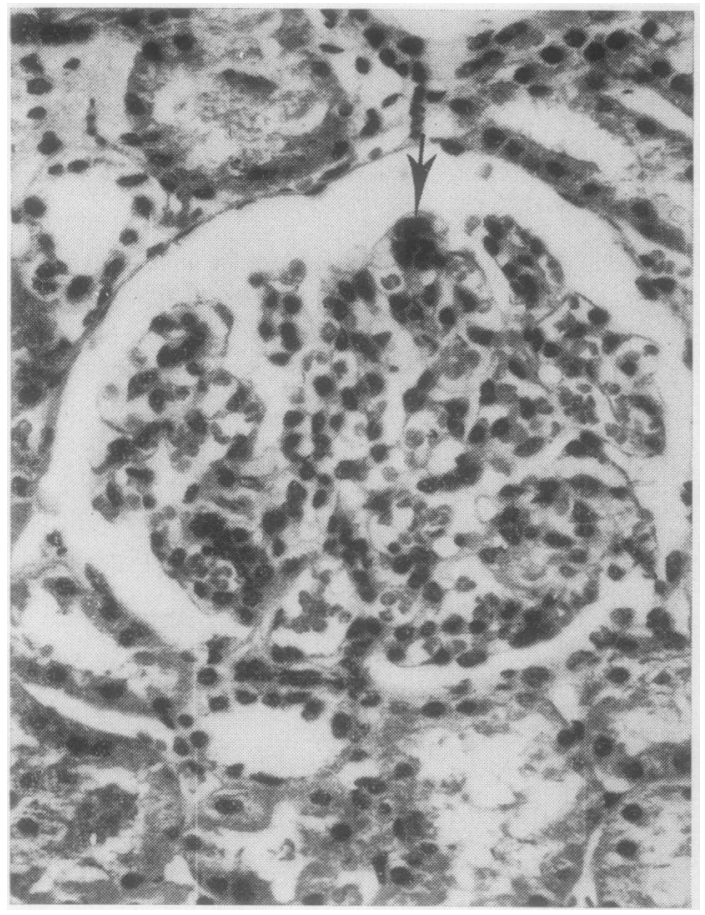

Fig. 11 .

Fig. 11 Case 4: a glomerulus showing mild focal hypercellularity (arrow). Note that the capillary wall is unaltered. $H$ and $E \times 380$.

Fig. 12 Case 4: electron micrograph of a portion of a glomerulus showing increased number of endothelial cells $(\mathrm{EN})$ in a capillary loop (CL). The basement membrane (GBM) is unaltered and the epithelial foot processes are fused $\times 6800$.

Fig. 12.

time his clinical condition has remained fairly static with resistant oedema and a slight elevation of urinary protein to $6 \cdot 1 \mathrm{~g}$ per 24 hours and blood urea to $61 \mathrm{mg} \%$.

\section{LIGHT MICROSCOPY}

The glomeruli observed in this biopsy showed only a rare focal proliferative lesion (Fig. 11), the remaining glomeruli being consistent with a minimal change lesion. No lesion was detected in extraglomerular vessels. No fluorescence was observed in any

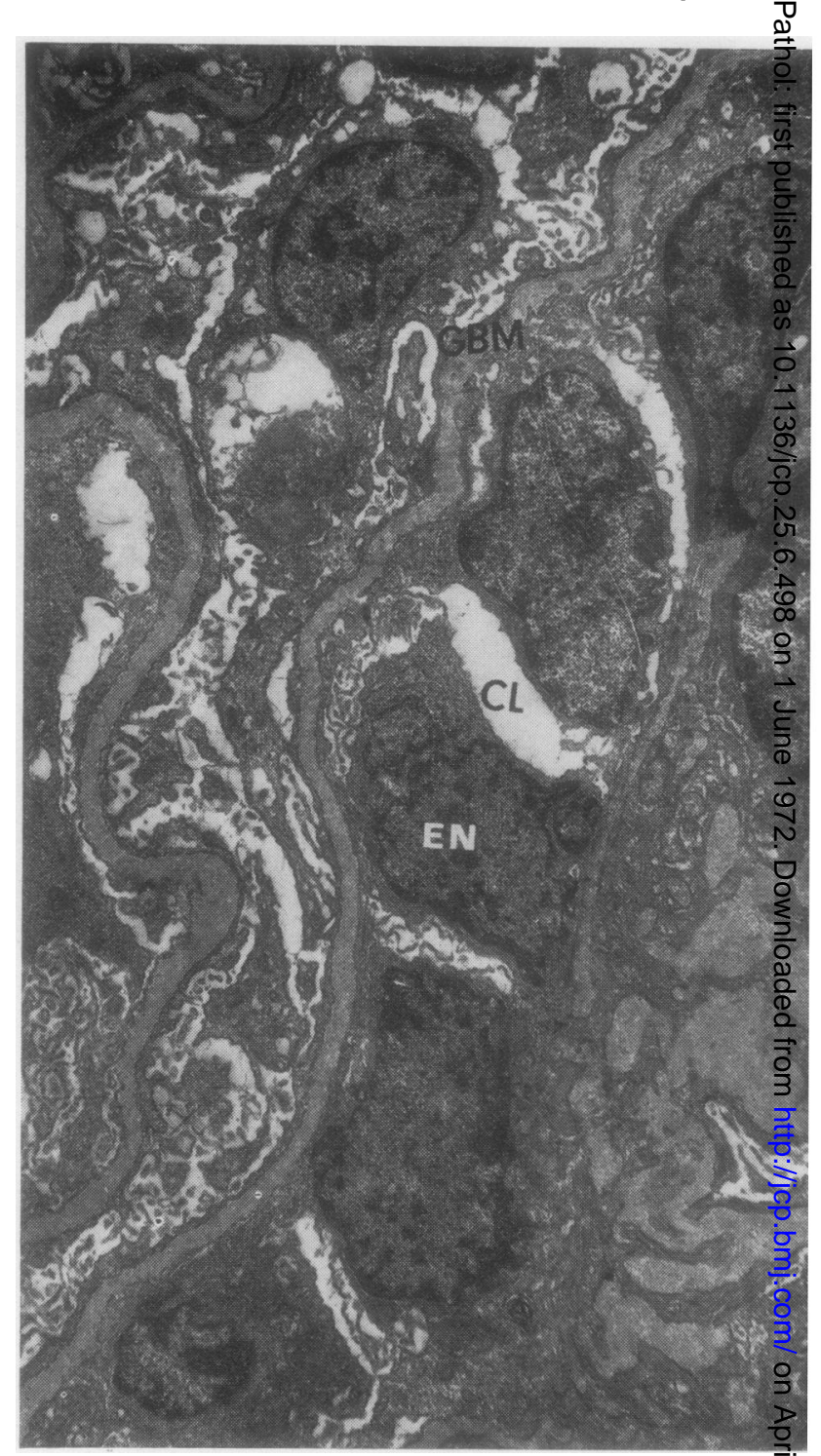

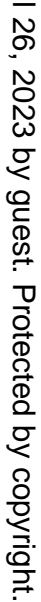




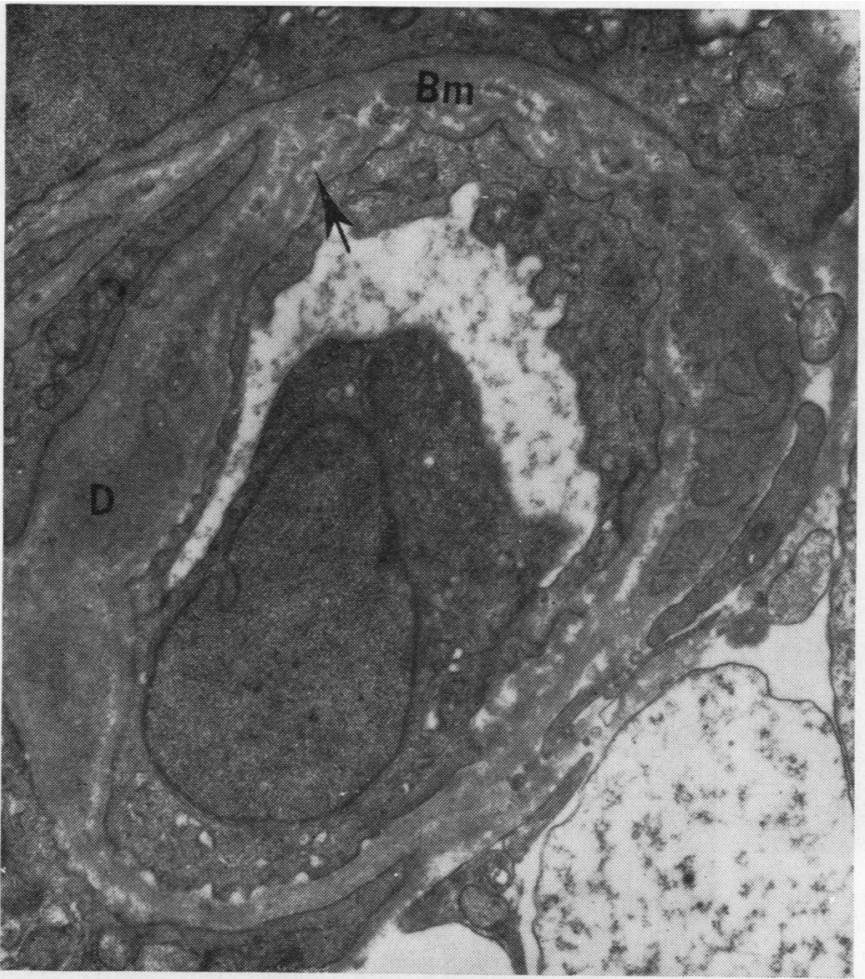

Fig. 13 Case 4: electron micrograph of an extraglomerular blood vessel showing osmiophilic deposits (D) in its basement membrane $(\mathrm{Bm})$ which split in places (arrow) $\times 6400$.

Fig. 14 Case 5: a glomerulus showing normal cellularity and normal capillary walls. $H$ and $E \times 400$.

Fig. 13.

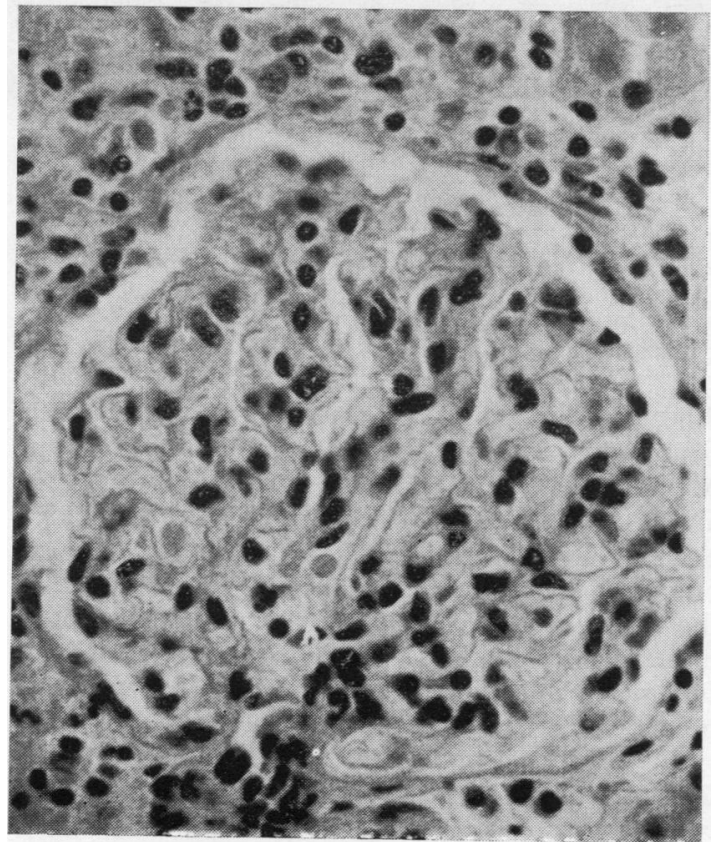

Fig. 14.
(Fig. 13) were noted within the basement membrane and appeared to split the membrane in areas. No fibrin thrombi were seen in capillaries.

\section{Case 5}

A 22-year-old man was found to have proteinuria and mild ankle oedema on routine medical examination. He was admitted to hospital for further investigation and was found to have ankle oedema $(++)$ and blood pressure $128 / 80 \mathrm{~mm} \mathrm{Hg}$. He had no history of upper respiratory tract infection. Laboratory investigations revealed urinary protein excretion of $3.7 \mathrm{~g}$ per 24 hours; total serum protein $5.2 \mathrm{~g} \%$ (albumin $2.1 \mathrm{~g} \%$ and globulin $3.1 \mathrm{~g} \%$ ), blood urea $40 \mathrm{mg} \%$, creatinine clearance $123 \mathrm{ml} / \mathrm{min}$, and serum cholesterol $210 \mathrm{mg} \%$. Renal biopsy was performed and the patient treated with steroids. He had a good response with marked reduction in proteinuria to $1.5 \mathrm{~g} / 24$ hours with elevation of total serum protein to $5.9 \mathrm{~g} \%$ (albumin $3.1 \mathrm{~g} \%$ ) and the oedema disappeared. His blood pressure was recorded at the last follow up as $130 / 75 \mathrm{~mm} \mathrm{Hg}$.

\section{LIGHT MICROSCOPY}

Examination of the renal biopsy showed no detect- 


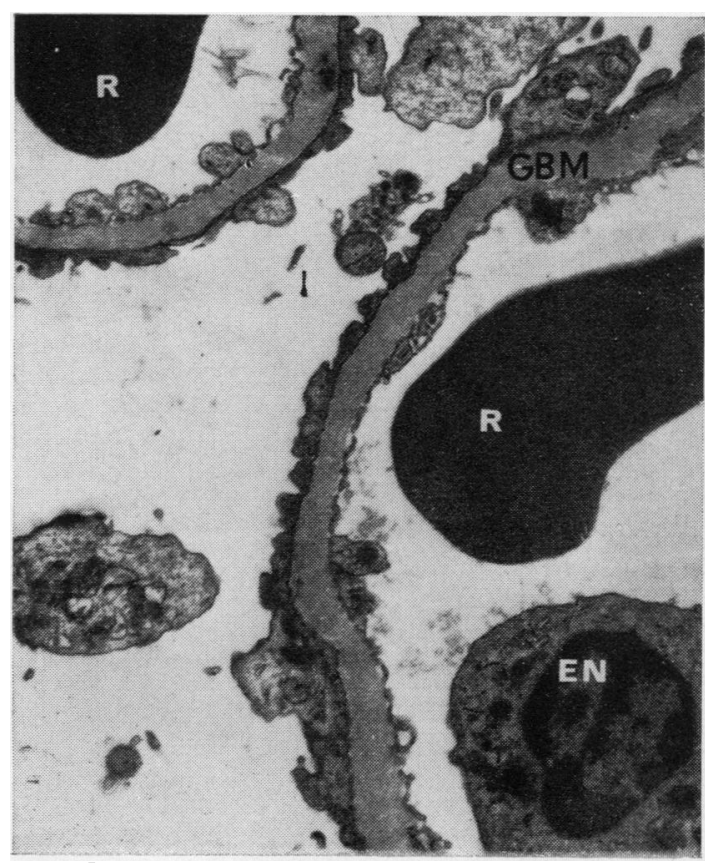

Fig. 15.

Fig. 15 Case 5: portions of two glomerular capillary loops containing an endothelial cell (EN) and two red blood cells (R). The basement membrane (GBM) is unaltered and the foot processes (arrow) are fused $\times 7100$.

Fig. 16 Case 5: portion of an extraglomerular blood vessel showing osmiophilic deposits (D) within the basement membrane $(\mathrm{Bm})$. Inside the lumen is a part of a red blood cell $(\mathrm{R}) \times 16700$.

able tubular or vascular lesion and the glomeruli were not hypercellular. There was no discernible glomerular capillary basement membrane thickening and the lesion was considered to be minimal change (Fig. 14). No fluorescence was observed with IgG, IgM, or C3 components of complement.

\section{ELECTRON MICROSCOPY}

The only glomerular lesion detected on electron microscopy was a fusion of epithelial foot processes over the apparently unaltered capillary basement membrane (Fig. 15). No deposits were seen. One of the four blocks examined contained a thick-walled extraglomerular blood vessel which showed numerous osmiophilic, electron-dense deposits situated within the basement membrane (Fig. 16).

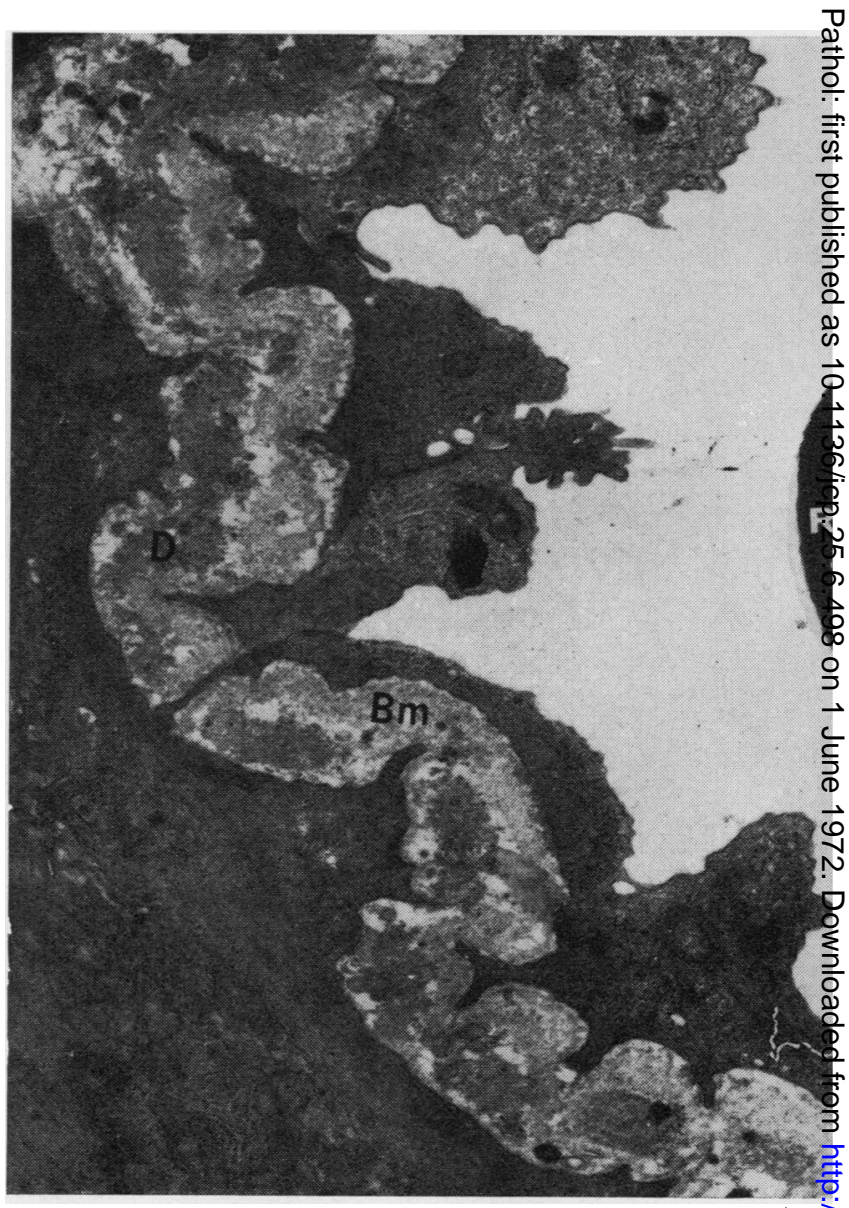

Fig. 16.

\section{Discussion}

Since the recognition of membranous glomerulonephritis by Bell (1950), many observers (Movat and McGregor, 1959; Spargo and Arnold, 1960; Spargo and Forland, 1967) have described the ultrastructural changes in this type of lesion. All agree that there are numerous electron-dense deposits situated towards the epithelial aspect of glomerular basement membrane. These deposits may be seen occasionally in Bowman's capsule, but have not been found in any other renal structure. Electron-dense deposits in the extraglomerular capillaries have been observed by Grishman and Churg (1964) in systemic lupus erythematosus in which glomeruli also contained prominent subendothelial osmiophilic deposits. 
Dachs, Churg, Mautner, and Grishman (1964) and Ehrenreich and Churg (1968) have described hyaline changes in renal blood vessels in cases of epimembranous nephropathy. These hyaline changes were seen in light microscopy and were either in elderly patients or in those with hypertension.

The three cases of epimembranous nephropathy described here showed electron-dense osmiophilic deposits in the walls of extraglomerular vessels. The distribution of these deposits in the arteriolar wall was different from those described by Biava, Dyrda, Genest, and Bencosme (1964), Fisher, Perez-Stable, and Pardo (1966), and Pardo, Fisher, Perez-Stable, and Rodnan (1966) in essential and renal types of hypertension and in progressive systemic sclerosis. Deposits in our cases were situated either on the outer aspect of or within the basement membrane, whereas those described in hypertension were situated subendothelially. In addition to the difference in site, the deposits in the present cases were finaly granular and were similar to those seen in relation to the glomerular basement membrane. The average size of granules forming these deposits in epimembranous nephropathy was approximately $400^{\circ} \mathrm{A}$, whereas those forming arteriolar hyaline in hypertension and progressive systemic sclerosis are up to $200^{\circ} \mathrm{A}$.

The arteriolar hyaline is thought to be derived either from the smooth muscle forming the vessel wall (Montgomery and Muirhead, 1954; McGee and Ashworth, 1963), or might constitute the deposits of substances of haematogenous origin, mainly plasma proteins (Biava et al, 1964; Fisher et al, 1966). Although the exact source and the mechanism of deposition of the extraglomerular arteriolar deposits described in epimembranous nephropathy are not known, we feel that pathogenically they may have a close association with the primary glomerular disease. The ultrastructural and fluorescent antibody studies in epimembranous nephropathy strongly suggest an immune pathogenesis responsible for the deposition of immune complexes (antigen-antibodycomplement complexes) along the glomerular basement membrane (McCluskey, 1970). In the absence of hypertension it is felt that as arteriolar deposits have a great structural resemblance to those seen in the glomeruli, they might be the result of filtration and subsequent deposition of circulating immune complexes under the influence of some additional factors of unknown nature.
The detection of extraglomerular vascular osmiophilic deposits in minimal change lesion and focal glomerulonephritis, however, remains unexplained in the absence of deposits within the glomeruli themselves.

Our thanks are due to Dr M. G. McGeown, Dr E. McEvoy, and Dr R. A. Womersley for providing us with clinical data and biopsy material from their patients; to Professor Sir John H. Biggart, CBE, for providing the facilities required; and to $\mathrm{Mr} \mathrm{S}$. Cameron and $\mathrm{Mr} \mathrm{P}$. Westwood for technical assistance with electron microscopy and $\mathrm{Mr} \mathrm{D}$. Mehaffey for photographs.

\section{References}

Bell, E. T. (1950). Renal Diseases, 2nd ed. Lea and Fabriger, Philadelphia, Kimpton, London.

Biava, C. G., Dyrda, I., Genest, J., and Bencosme, S. A. (1964). Renal hyaline arteriolosclerosis. An electron microscope study. Amer. J. Path., 44, 349-363.

Churg, J., Grishman, E., Goldstein, M. H., Yunis, S. L., and Porush, J. G. (1965). Idiopathic nephrotic syndrome in adults: a study and classification based on renal biopsies. New Engl. J. Med., 272, $165-174$.

Dachs, S., Churg, J., Mautner, W., and Grishman, E. (1964). Diabetic nephropathy. Amer. J. Path., 44, 155-168.

Ehrenreich, T., and Churg, J. (1968). Pathology of membranous nephropathy. Path. Ann., 3, 145-186.

Fisher, E. R., Perez-Stable, E., and Pardo, V. (1966). Ultrastructural studies in hyalinisation. I. Comparison of renal vascular and juxtaglomerular cell alterations in essential and renal hypertension in man. Lab. Invest., 14, 1409-1433.

Grishman, E., and Churg, J. (1964). Extraglomerular 'wire loops' in systemic lupus erythematosus. Amer. J. Cardiol., 14, 888-889.

McCluskey, R. T. (1970). Evidence for immunologic mechanisms in several forms of human glomerular diseases. Bull. N.Y. Acad. Med., 46, 769-788.

McGee, W. G., and Ashworth, C. T. (1963). Fine structure of chronic hypertensive arteriopathy in the human kidney. Amer. J. Path., 43, 273-299.

Montgomery, P. O., and Muirhead, E. E. (1954). A microscopic study of arterioles in benign and malignant hypertension. Amer. $J$. Path., 30, 1181-1189.

Movat, H. Z., and McGregor, D. D. (1959). The fine structure of the glomerulus in membranous glomerulonephritis (Lipoid nephrosis) in adults. Amer. J. clin. Path., 32, 109-127.

Pardo, V., Fisher, E. R., Perez-Stable, E., and Rodnan, G. P. (1966). Ultrastructural studies in hypertension. II. Renal vascular changes in progressive systemic sclerosis. Lab. Invest., 15, 1434-1441.

Spargo, B., and Arnold, J. D. (1960). Glomerular extrinsic membranous deposits with the nephrotic syndrome. Ann. N.Y. Acad. Sci., 86, 1043-1063.

Spargo, B. H., and Forland, M. (1967). The differential diagnosis of glomerular ultrastructural lesions. In Proceedings of the 3rd International Congress of Nephrology, Washington, 1966, Vol. 2, pp. 33-44. Karger, Basle and New York.

White, R. H. R. (1969). Epimembranous nephropathy. Lancet, 2, 746. 